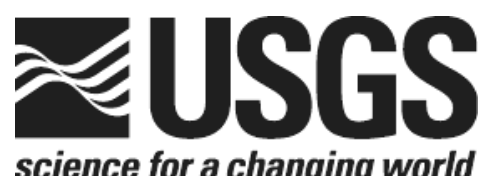

\title{
Determination of the $\delta\left({ }^{18} 0 /{ }^{16} 0\right)$ of Water: RSIL Lab Code 489
}

Chapter 2 of

Book 10, Methods of the Reston Stable Isotope Laboratory

Section C, Stable Isotope-Ratio Methods

Techniques and Methods 10-C2 


\section{This page left blank intentionally.}




\section{Determination of the $\delta\left({ }^{18} 0 /{ }^{16} 0\right)$ of Water: RSIL Lab Code 489}

By Kinga Révész and Tyler B. Coplen

Chapter 2 of

Book 10, Methods of the Reston Stable Isotope

Laboratory

Section C, Stable Isotope-Ratio Methods

Edited by Kinga Révész and Tyler B. Coplen

Techniques and Methods 10-C2 


\title{
U.S. Department of the Interior DIRK KEMPTHORNE, Secretary
}

\section{U.S. Geological Survey Mark D. Myers, Director}

U.S. Geological Survey, Reston, Virginia 2008

\author{
For sale by U.S. Geological Survey, Information Services \\ Box 25286, Denver Federal Center \\ Denver, CO 80225 \\ For more information about the USGS and its products: \\ Telephone: 1-888-ASK-USGS \\ World Wide Web: http://www.usgs.gov/
}

Any use of trade, product, or firm names in this publication is for descriptive purposes only and does not imply endorsement by the U.S. Government.

Although this report is in the public domain, permission must be secured from the individual copyright owners to reproduce any copyrighted material contained within this report.

Suggested citation:

Révész, Kinga, and Coplen, Tyler, B., 2008, Determination of the $\delta\left({ }^{18} 0 /{ }^{16} 0\right)$ of water: RSIL lab code 489, chap. C2 of Révész, Kinga, and Coplen, Tyler B., eds., Methods of the Reston Stable Isotope Laboratory: U.S. Geological Survey Techniques and Methods, 10-C2, $28 \mathrm{p}$. 


\section{Foreword}

The Reston Stable Isotope Laboratory (RSIL) provides stable isotope analyses on a routine basis for a large user community within the U.S. Geological Survey (USGS) and elsewhere. The RSIL also serves the USGS National Research Program (NRP) through its project on Stable Isotope Fractionation in Hydrologic Processes. The NRP conducts basic and problem-oriented hydrologic research in support of the mission of the USGS. The stable isotope project conducts research on the use of isotope-ratio measurements in studies of water resources and environmental quality. One objective of this project is to develop new techniques for isotopic analysis of $\mathrm{H}, \mathrm{N}, \mathrm{O}, \mathrm{C}$, and $S$ in environmental samples. New analytical techniques expand the range of tools available for studying the movement of those elements in hydrologic and biogeochemical systems. Another objective of the project is to test new applications of isotope measurements in specific field settings. Field studies of isotope behavior have contributed to understanding of water-supply sustainability, ground-water/surface-water interactions, paleoclimate history, biologic cycling of nutrients, ground-water contamination, and natural remediation. This project also contributes to the improvement of measurement science and the development of isotope databases.

Book 10 of the Techniques and Methods Series of the USGS contains detailed descriptions of methods of the RSIL, including routine analytical methods called standard operating procedures (SOPs), along with safety guidelines, maintenance procedures, and other information about the operation of the RSIL. Section C of Book 10 contains the SOPs for a variety of methods to measure stable isotope ratios, each of which constitutes a chapter. Each chapter is limited to a narrow field of subject matter to permit flexibility in revision as the need arises.

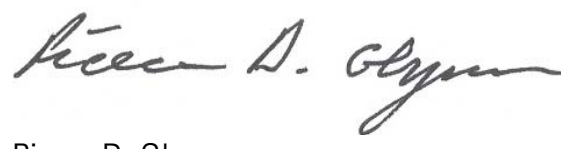

Pierre D. Glynn

Chief, Branch of Regional Research, Eastern Region 
This page left blank intentionally. 


\section{Contents}

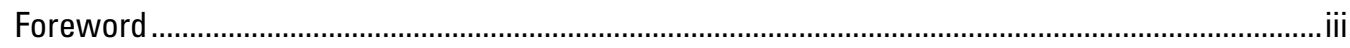

Conversion Factors ................................................................................................................

Acronyms and Abbreviations …………………….............................................................. vii

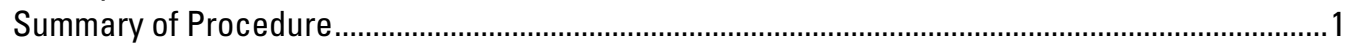

Reporting Units and Operational Range ………........................................................................

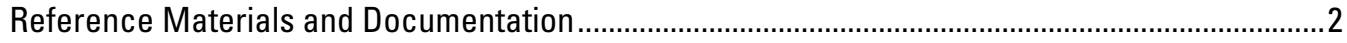

Reference Materials Used, Storage Requirements, and Shelf Life ..................................2

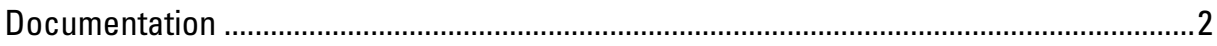

Labware, Instrumentation, and Reagents .....................................................................................

Sample Collection, Preparation, Analysis, Retention Times, and Disposal.......................................

Sample Containers, Preservation, and Handling Requirements ........................................ 3

Sample Preparation and Time Requirements.................................................................. 4

Performing the Analysis and Time Requirements ........................................................

Problematic Samples......................................................................................................

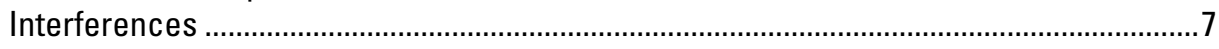

Troubleshooting and Bench Notes ..............................................................................

Maintenance and Maintenance Records ……………...................................................

Sample Retention Time and Disposal ...............................................................................

Data Acquisition, Processing, Evaluation, Quality Control, and Quality Assurance ........................8

Laboratory Information Management System for Light Stable Isotopes (LIMS-LSI) ........8

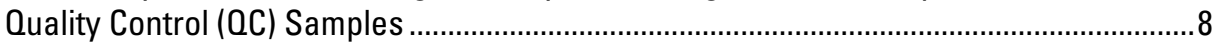

Acceptance Criteria for All OC Samples .........................................................................

Corrective Action Requirements .........................................................................................

Responsible Parties for All QA/QC Functions for Procedures Covered in RSIL SOPs.......9

Data Management and Records...................................................................................

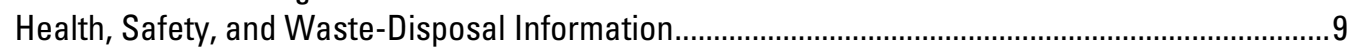

Applicable Health and Safety Issues.............................................................................

Personal Protection ……………………………………………………....

Electrical Hazards ................................................................................................

Chemical Hazards ................................................................................................ 10

Gas Cylinder Handling .................................................................................... 10

Specific Waste-Disposal Requirements ………....................................................... 10

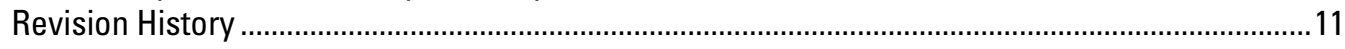

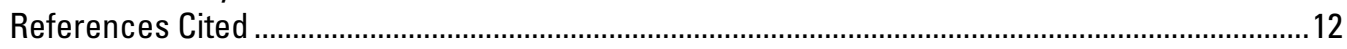

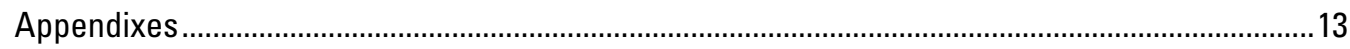

A. Step-by-Step Procedure to Log In Samples to LIMS-LSI .........................................13

B. Step-by-Step Procedure to Print a Template and a Samples-to-Be-Analyzed List .. 19

C. Step-by-Step Procedure to Prepare and Analyze Samples on the $\mathrm{CO}_{2}$

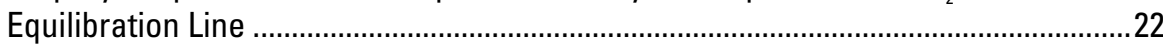

D. Step-by-Step Procedure for $\mathrm{CO}_{2}$ Mass Spectrometer Checklist ................................25

E. Step-by-Step Procedure to Determine and Apply Correction Factors and

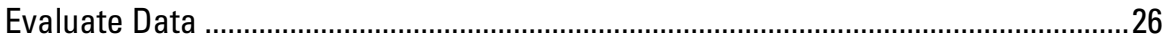

F. Step-by-Step Procedure to Leak Check Valves ..........................................................27

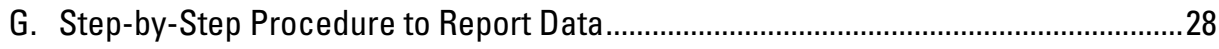




\section{Figures}

1. Diagram of VG Micromass water equilibration unit, sample-reference switching

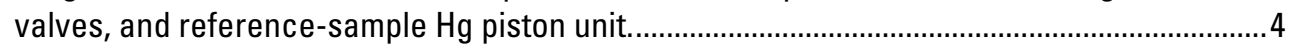

2. Schematic of a dual-inlet isotope-ratio mass spectrometer ....................................................... 


\section{Conversion Factors}

\begin{tabular}{|c|c|c|}
\hline Multiply & By & To Obtain \\
\hline \multicolumn{3}{|c|}{ Length } \\
\hline micrometer $(\mu \mathrm{m})$ & 0.00003937 & inch (in.) \\
\hline millimeter (mm) & 0.03937 & inch (in.) \\
\hline centimeter $(\mathrm{cm})$ & 0.3937 & inch (in.) \\
\hline meter (m) & 3.281 & foot $(\mathrm{ft})$ \\
\hline \multicolumn{3}{|c|}{ Volume } \\
\hline microliter $(\mu \mathrm{L})$ & $0.0610210^{-3}$ & cubic inch $\left(\right.$ in $\left.^{3}\right)$ \\
\hline milliliter (mL) & 0.06102 & cubic inch $\left(\mathrm{in}^{3}\right)$ \\
\hline cubic centimeter $\left(\mathrm{cm}^{3}\right)$ & 0.06102 & cubic inch $\left(\right.$ in $\left.^{3}\right)$ \\
\hline liter (L) & 61.02 & cubic inch $\left(\mathrm{in}^{3}\right)$ \\
\hline \multicolumn{3}{|c|}{ Mass } \\
\hline nanogram $(\mathrm{ng})=10^{-3} \mu \mathrm{g}$ & $3.527 \times 10^{-11}$ & ounce (oz) \\
\hline microgram $(\mu \mathrm{g})=10^{-3} \mathrm{mg}$ & $3.527 \times 10^{-8}$ & ounce (oz) \\
\hline milligram $(\mathrm{mg})=10^{-3} \mathrm{~g}$ & $3.527 \times 10^{-5}$ & ounce (oz) \\
\hline $\operatorname{gram}(\mathrm{g})=10^{-3}(\mathrm{~kg})$ & $3.527 \times 10^{-2}$ & ounce (oz) \\
\hline kilogram $(\mathrm{kg})=10^{3} \mathrm{~g} ; 10^{6} \mathrm{mg} ; 10^{9} \mu \mathrm{g} ; 10^{12} \mathrm{ng}$ & 2.205 & pound $(\mathrm{lb})$ \\
\hline \multicolumn{3}{|c|}{ Density } \\
\hline gram per cubic centimeter $\left(\mathrm{g} / \mathrm{cm}^{3}\right)$ & 0.5780 & ounce per cubic inch $\left(0 z / \mathrm{in}^{3}\right)$ \\
\hline \multicolumn{3}{|c|}{ Temperature } \\
\hline Celsius $\left({ }^{\circ} \mathrm{C}\right)$ & ${ }^{\circ} \mathrm{F}=9 / 5\left({ }^{\circ} \mathrm{C}\right)+32$ & Fahrenheit ( $\left.{ }^{\circ} \mathrm{F}\right)$ \\
\hline \multicolumn{3}{|c|}{ Pressure (force/area) } \\
\hline kilopascal (kPa) & $9.869 \times 10^{-3}$ & atmosphere, standard (atm) \\
\hline kilopascal (kPa) & $1.450 \times 10^{-1}$ & $\begin{array}{l}\text { pound-force/square inch } \\
\text { (psi) }\end{array}$ \\
\hline kilopascal (kPa) & $1.000 \times 10^{-2}$ & bar \\
\hline kilopascal (kPa) & $2.961 \times 10^{-1}$ & inches of mercury at $60^{\circ} \mathrm{F}$ \\
\hline
\end{tabular}

\section{Acronyms and Abbreviations}

ANSI

ASR

DI-IRMS

DIW
American National Standards Institute analytical services request dual inlet isotope-ratio mass spectrometer deionized water 
$\begin{array}{ll}\text { IAEA } & \text { International Atomic Energy Agency } \\ \text { IRMS } & \text { isotope-ratio mass spectrometer } \\ \text { LIMS-LSI } & \text { Laboratory Information Management System for Light Stable Isotopes } \\ \text { MSDS } & \text { Material Safety Data Sheets } \\ m / z & \text { mass-to-charge ratio } \\ \text { NFPA } & \text { National Fire Protection Association } \\ \text { NIST } & \text { National Institute of Standards and Technology } \\ \text { NWIS } & \text { National Water Information System } \\ \text { NWQL } & \text { National Water Quality Laboratory (USGS) } \\ \text { per mill, \%o } & \text { 1/1000 } \\ \text { pF } & \text { picofarad } \\ \text { QA } & \text { quality assurance } \\ \text { QC } & \text { quality control } \\ \text { QC/QA } & \text { quality control/quality assurance } \\ \text { RSIL } & \text { Reston Stable Isotope Laboratory } \\ \text { SLAP } & \text { Standard Light Antarctic Precipitation } \\ \text { SOP } & \text { standard operating procedure } \\ \text { USGS } & \text { U.S. Geological Survey } \\ \text { VSMOW } & \text { Vienna Standard Mean Ocean Water }\end{array}$

\section{Symbols}

$\begin{array}{ll}\Omega & \text { ohm } \\ < & \text { less than } \\ > & \text { greater than } \\ \leq & \text { less than or equal } \\ \geq & \text { greater than or equal }\end{array}$




\title{
Determination of the $\delta\left({ }^{18} 0 /{ }^{16} 0\right)$ of Water: RSIL Lab Code 489
}

\author{
By Kinga Révész and Tyler B. Coplen
}

\section{Summary of Procedure}

The purpose of the technique described by the Reston Stable Isotope Laboratory (RSIL) lab code 489 is to present a method to determine the $\delta\left({ }^{18} \mathrm{O},{ }^{16} \mathrm{O}\right)$, abbreviated as $\delta^{18} \mathrm{O}$, of water. This $\delta^{18} \mathrm{O}$ measurement of water also is a component of National Water Quality Laboratory (NWQL in USGS) schedules 1142 and 1172. Water samples are loaded into glass sample containers on a vacuum manifold to equilibrate gaseous $\mathrm{CO}_{2}$ at constant temperature $\left(25^{\circ} \mathrm{C}\right)$ with water samples. After loading water samples on the vacuum manifold, air is evacuated through capillary to avoid evaporation, and $\mathrm{CO}_{2}$ is added. The samples are shaken to increase the equilibration rate of water and $\mathrm{CO}_{2}$. When isotopic equilibrium has been attained, an aliquot of $\mathrm{CO}_{2}$ is extracted sequentially from each sample container, separated from water vapor by means of a dry ice trap, and introduced into a dual-inlet isotope-ratio mass spectrometer (DIIRMS) for determination of the $\delta^{18} \mathrm{O}$ value. There is oxygen isotopic fractionation between water and $\mathrm{CO}_{2}$, but it is constant at constant temperature. The DI-IRMS is a DuPont double-focusing mass spectrometer. It has a double collector. One ion beam passes through a slit in a forward collector and is collected in the rear collector. The other ion beams are collected in the front collector. The instrument is capable of measuring mass/charge $(\mathrm{m} / \mathrm{z}) 44$ and 45 or 44 and 46 by changing the ion-accelerating voltage under computer control. The ion beams from these $m / z$ values are as follows: $m / z, 44=\mathrm{CO}_{2}={ }^{12} \mathrm{C}^{16} \mathrm{O}^{16} \mathrm{O}$, $m / z 45=\mathrm{CO}_{2}={ }^{13} \mathrm{C}^{16} \mathrm{O}^{16} \mathrm{O}$ primarily, and $m / z, 46=\mathrm{CO}_{2}={ }^{12} \mathrm{C}^{16} \mathrm{O}^{18} \mathrm{O}$ primarily. The data acquisition and control software calculates $\delta^{18} \mathrm{O}$ values.

\section{Reporting Units and Operational Range}

Variations in isotopic compositions typically are small. Stable isotope-number ratios commonly are measured and expressed as the relative difference in the ratio of the number of the less-abundant isotope (usually the heavy isotope) to the number of the more abundant isotope (usually the light isotope) of a sample with respect to a reference. This relative difference is designated $\delta\left({ }^{i} \mathrm{E}\right)$, and it is defined according to equation 1:

$$
\delta\left({ }^{i} \mathrm{E}\right)=\delta\left({ }^{i} \mathrm{E},{ }^{j} \mathrm{E}\right)=\delta^{i} \mathrm{E}=\frac{N_{\mathrm{B}}\left({ }^{i} \mathrm{E}\right) / N_{\mathrm{B}}\left({ }^{j} \mathrm{E}\right)-N_{\text {std }}\left({ }^{i} \mathrm{E}\right) / N_{\text {std }}\left({ }^{j} \mathrm{E}\right)}{N_{\text {std }}\left({ }^{i} \mathrm{E}\right) / N_{\text {std }}\left({ }^{j} \mathrm{E}\right)}
$$

where $\delta\left({ }^{i} \mathrm{E}\right)$ refers to the delta value of isotope number $i$ and $j$ (heavy and light isotopes, respectively) of element $\mathrm{E}$ of sample $\mathrm{B}$ relative to an international measurement standard (std); $N_{\mathrm{B}}\left({ }^{i} \mathrm{E}\right) / N_{\mathrm{B}}\left({ }^{j} \mathrm{E}\right)$ and $\left.N_{\text {std }}{ }^{i} \mathrm{E}\right) / N_{\text {std }}{ }^{j} \mathrm{E}$ ) are the ratios of the number of isotopes in unknown B and the international measurement standard. A positive $\delta\left({ }^{i} \mathrm{E}\right)$ value indicates that the unknown is more enriched in the heavy isotope than the international measurement standard. A negative $\delta\left({ }^{i} \mathrm{E}\right)$ value indicates that the unknown is depleted in the heavy isotope relative to the international measurement standard. The symbol $\delta\left({ }^{i} \mathrm{E}\right)$ is 
commonly shortened to $\delta{ }^{i} \mathrm{E}$ and has been reported in parts per hundred (\% or percent), parts per thousand (\%o or per mill), and parts per ten thousand. For stable oxygen isotope-number ratios, $\delta^{18} \mathrm{O}$ is written as follows:

$$
\delta^{18} \mathrm{O}=\delta^{18}(\mathrm{O})=\delta\left({ }^{18} \mathrm{O},{ }^{16} \mathrm{O}\right)=\frac{N_{\mathrm{B}}\left({ }^{18} \mathrm{O}\right) / N_{\mathrm{B}}\left({ }^{16} \mathrm{O}\right)-N_{\text {std }}\left({ }^{18} \mathrm{O}\right) / N_{\text {std }}\left({ }^{16} \mathrm{O}\right)}{N_{\text {std }}\left({ }^{18} \mathrm{O}\right) / N_{\text {std }}\left({ }^{16} \mathrm{O}\right)}
$$

The international measurement standards are Vienna Standard Mean Ocean Water (VSMOW) and Standard Light Antarctic Precipitation (SLAP) (Coplen, 1994). By interspersing local laboratory isotopic reference waters with isotopic compositions calibrated with international reference waters (VSMOW and SLAP) among the unknowns, the $\delta^{18} \mathrm{O}$ values of unknown waters can be determined (Coplen, 1988, 1996). The $\delta^{18} \mathrm{O}$ measurements are made with a DI-IRMS, which measures, alternatively, the isotopenumber ratios of the unknown $\mathrm{CO}_{2}$ gas and of the "working reference" $\mathrm{CO}_{2}$ gas.

The system was tested by analyzing water samples with known $\delta^{18} \mathrm{O}$ values. The $\delta^{18} \mathrm{O}$ values of test samples ranged from approximately -55 to $+5 \%$, which covers the range of $\delta^{18} \mathrm{O}$ of natural water. The routine analysis requires $2 \mathrm{~mL}$ water; however, the system is capable of analyzing samples as small as $0.2 \mathrm{~mL}$ with minimal reduction in accuracy. It was found that the precision and accuracy of the results were acceptable $( \pm 0.07 \%$ ) (Coplen and others, 1983), and memory between sample vessels was below detection $( \pm 0.07 \%$ )

\section{Reference Materials and Documentation}

\section{Reference Material Used, Storage Requirements, and Shelf Life}

The international measurement standards for $\delta^{18} \mathrm{O}$ measurements are VSMOW [also distributed by the National Institute of Standards and Technology (NIST) as RM 8535] and SLAP (also distributed by NIST as RM 8537) (Coplen 1994). They are, respectively, assigned a $\delta^{18} \mathrm{O}$ value of $0 \%$ and of $-55.5 \%$, exactly. The RSIL has used VSMOW and SLAP reference waters to calibrate local laboratory reference waters as needed. These include deionized water (DIW) with a $\delta^{18} \mathrm{O}$ value of approximately $-6.2 \%$ and Antarctic water with a value of approximately $-51.3 \%$. Approximately $40 \mathrm{~L}$ of each was homogenized, loaded into $10-\mathrm{mL}$ glass ampoules, sealed with a glass-blowing torch, and sterilized to prevent biological growth and to identify any ampoules with leaks. These local laboratory reference waters are stored in the RSIL, and their shelf life is indefinite.

\section{Documentation}

All calibration results are stored in the Laboratory Information Management System for Light Stable Isotopes (LIMS-LSI) (Coplen, 2000) under sample identifiers with a prefix of W. Local laboratory reference waters analyzed daily include W-62000 and W-63333, which are DIW and Antarctic waters, respectively.

\section{Labware, Instrumentation, and Reagents}

The apparatus consists of three components: (1) a $\mathrm{CO}_{2}$-water equilibration unit, (2) DI-IRMS, and (3) computer software. 
The VG Micromass water equilibration unit (fig. 1) is constructed to hold 48 samples and has an air bath that ensures a temporal and spatial temperature variation of better than $\pm 0.3{ }^{\circ} \mathrm{C}$. The gas-handling system is constructed of four stainless steel manifolds, each of which has 12 sample-port valves. Computer control of each valve is achieved by energizing 50-V Peter Paul solenoid valves. The equilibration unit has one mechanical vacuum pump system to achieve a vacuum of $10^{-1} \mathrm{~Pa}$. Sample vessels consist of glass 15 -mL containers with 3/8-in. tops that slide into 3/8-in. Cajon O-ring fittings furnished with a built-in capillary. The equilibration is promoted by shaking each manifold using a solenoid drive.

The DI-IRMS is a modified DuPont 491 mass spectrometer (fig. 2) with a double-collecting Faraday cup collector (Coplen, 1973). In the DI-IRMS, gas molecules are ionized in a source by electrons emitted from a hot filament. The ions are accelerated into an energy analyzer, separated in a magnetic field, and collected in a Faraday cup collector. This ion geometry provides double focusing of ions. The ion-beam intensities are measured with electrometers. The feedback resistors on the cup- 1 and -2 electrometers are approximately $1 \times 10^{9}$ and $5 \times 10^{10}$, respectively. The response speeds of each electrometer are matched by slowing the response speed of the cup-1 electrometer with a resistor-capacitor response-speed filter. The mass spectrometer has an ion-beam monitor located between the energy analyzer and the magnetic analyzer, which provides the intensity of the total ion current. The ratio of the beam monitor current to the $m / z=44$ current for samples and reference gases gives a good determination of sample contamination.

Each sample is loaded into a computer-controlled sample piston (Coplen, 1981). One computercontrolled working-reference gas piston feeds gas into the reference capillary.

The Microsoft Visual Basic data acquisition and control software is designed to (1) control the sample preparation unit, (2) control the DI-IRMS, (3) acquire data from the DI-IRMS, and (4) process and store data directly to the LIMS-LSI.

\section{Sample Collection, Preparation, Analysis, Retention Times, and Disposal}

\section{Sample Container, Preservation, and Handling Requirements}

Each sample is collected in a 60-mL glass bottle with a Polyseal conical insert cap to minimize evaporation. Bottles are provided at no cost by the RSIL on request through e-mail to isotopes@usgs.gov. The bottles are labeled with isotopes whose concentrations are to be determined along with the respective laboratory code or schedule number. In the field, bottles should be filled with samples by overflowing directly from sample collection or processing devices, filtered or not filtered. Before capping the bottles, some water should be poured out until the water level is at the bottle shoulder; this will prevent the bottle from breaking if it freezes during transit to the RSIL. Samples could be collected in polyethylene bottles with no headspace. A minimum of $5 \mathrm{~mL}$ of water is required unless special arrangements are made in advance with RSIL. Regardless of the amount of sample collected, the bottle size should be matched to the sample size; that is, bottles should be at least three-quarters full to minimize evaporation effects.

No treatment, preservation, or special shipping is required.

\section{Sample Preparation and Time Requirements}

Sample preparation involves logging samples in to the LIMS-LSI. The logging-in procedure involves logging samples in batches to LIMS-LSI that could contain from 1 to 100 samples per batch (also called a project), printing labels for each sample, and printing a summary project report. Each sample label contains the Field ID (the identifier by which the sample submitter knows each sample) and the unique 
RSIL Lab ID assigned by the LIMS-LSI. The summary project report is inserted into a three-ring binder titled "Samples in Progress."

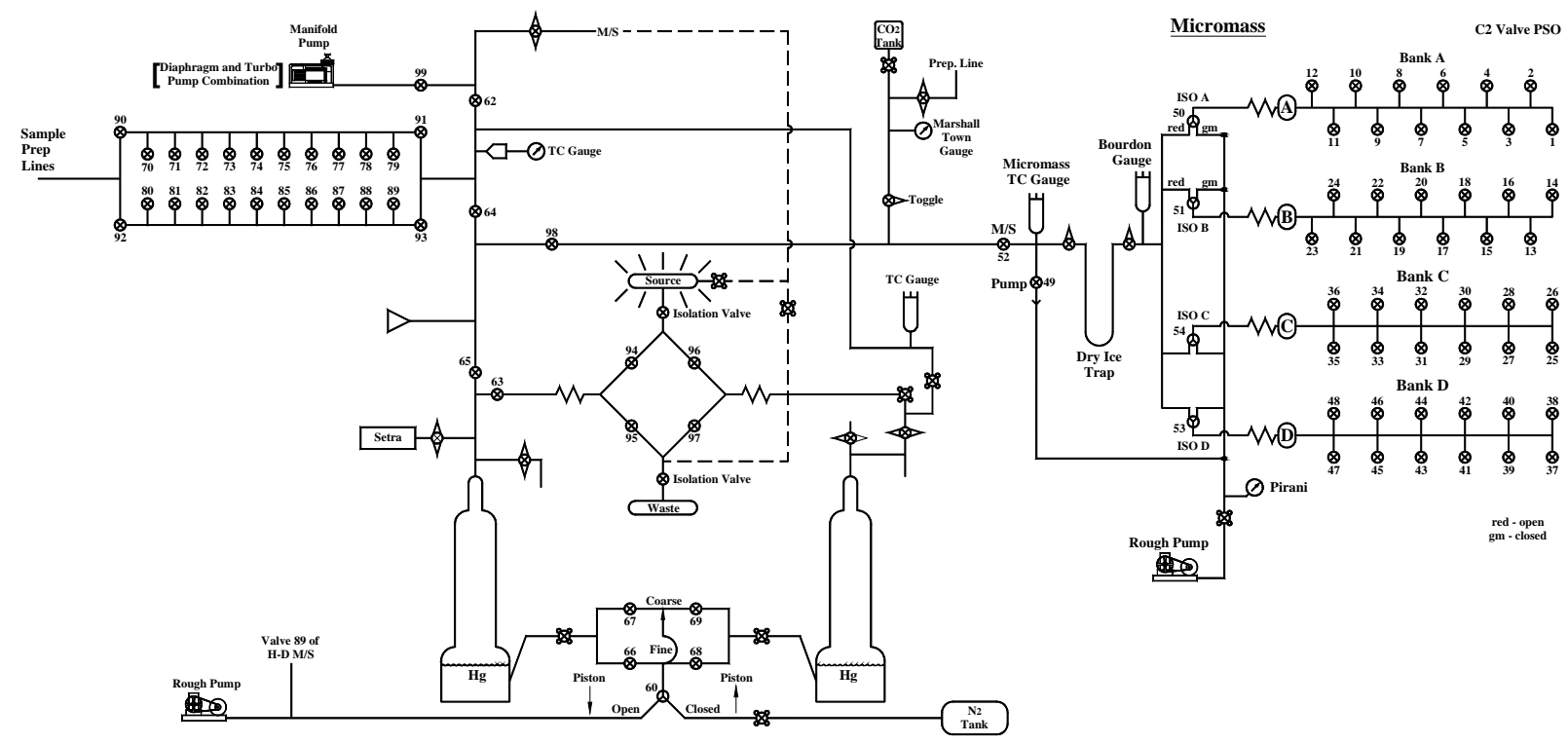

Figure 1. Diagram of VG Micromass water equilibration unit, sample-reference switching valves, and reference-sample Hg piston unit.

If samples are submitted through the USGS NWQL, the Field ID is a unique number for each sample assigned according to NWQL guidelines; this unique number is written on the analytical services request (ASR) form accompanying a sample, and the ASR information is entered into the LIMS-LSI system. This information is e-mailed to the submitter of the samples for identification of any errors and subsequently emailed to NWQL. Copies of the ASR forms are mailed to NWQL. The step-by-step procedure to log in samples to LIMS-LSI is given in Appendix A.

The time requirement for preparing the samples as described earlier is approximately 1 working day.

\section{Performing the Analysis and Time Requirements}

As many as 48 water samples are analyzed daily. Using the sample work order/worksheet, which is created by LIMS-LSI by printing a "Template" from the "Samples to Be Analyzed Form" (The step-bystep procedure for this is found in Appendix B), the analyst sets up the unknowns and local laboratory reference waters to be analyzed. The method is based on that of Epstein and Mayeda (1953) and Roether (1970). Each sample vessel is loaded with $2 \mathrm{~mL}$ of water. To remove air in sample vessels, they are evacuated through built-in capillaries. After satisfactory evacuation, $\mathrm{CO}_{2}$ is added simultaneously to all 48 vessels to a pressure of $50 \mathrm{kPa}$. The temperature controller is powered on and maintains the temperature at $27.00 \pm 0.1^{\circ} \mathrm{C}$. The current procedure, which includes the sections "System Preparation," "Water Sample Preparation," and "Starting Analysis," is given in Appendix C. The systematic procedure is listed in the "Lab Procedures" binder. The supervisor should review suggested changes before they are adopted. 


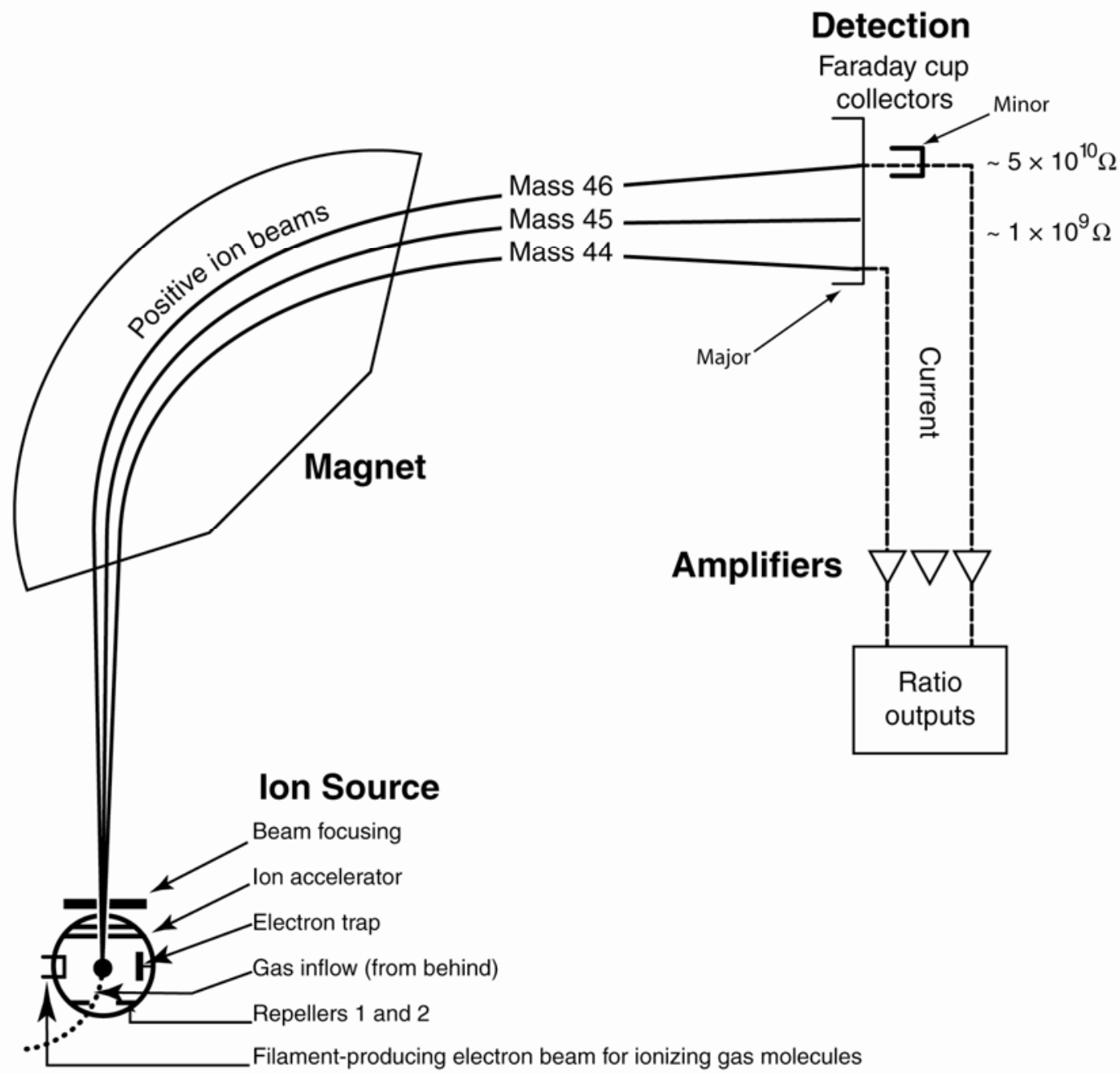

Figure 2. Schematic of a dual-inlet isotope-ratio mass spectrometer (DI-IRMS) (modified from Clark and Fritz, 1997).

Before starting isotopic analyses of the samples, the analyst checks to make sure that the DI-IRMS and its preparation system are functioning properly by checking off items on the $\mathrm{CO}_{2}$ mass-spectrometer checklist, which is provided in Appendix D. This checklist is replaced weekly and saved for analytical audits.

The date and time $\mathrm{CO}_{2}$ is added to samples is recorded daily on a new sheet and clipped in a binder with the mass-spectrometer printout of the samples to be analyzed. Any special comments are recorded on this daily record, which is saved for laboratory audits. If samples are saline or the sample volume is less than $2 \mathrm{~mL}$, the equilibration time is increased substantially ( $24 \mathrm{~h}$ is not uncommon). To analyze each sample, the pneumatically actuated valve confining the water and equilibrated $\mathrm{CO}_{2}$ is opened to the sample piston for approximately $12 \mathrm{~s}$ to expand approximately $90 \%$ of the $\mathrm{CO}_{2}$ from the sample vessel into the piston. Trace water is removed from the $\mathrm{CO}_{2}$ by trapping it with a U-tube trap filled with a dryice slush. Accumulated water is removed daily. Pressure adjustment in the sample in the piston is performed with an absolute pressure transducer; finer adjustment is performed with the $m / z=44$ ionbeam voltage. Samples are analyzed in turn. The $\delta^{18} \mathrm{O}$ values are normalized to the VSMOW-SLAP scale by the mass spectrometric software. The calculated delta value is called the penultimate delta, and it is saved in real time in the LIMS-LSI database. 
Final daily correction factors are determined on the basis of the daily analyses of local laboratory reference waters using equations 3 and 4, which are represented with numerical values:

$$
\begin{aligned}
& -6.21 \% \text { o }=m \times \delta_{\mathrm{W}-50000, \mathrm{VSMOW}^{18} \mathrm{O}+b} \\
& -51.26 \%=m \times \delta_{\mathrm{W}-63333, \mathrm{VSMOW}^{18} \mathrm{O}+b}
\end{aligned}
$$

The values $-6.21 \%$ and $-51.26 \%$ are the values of secondary reference waters that have been calibrated using the international reference waters VSMOW and SLAP. The $\delta^{18} \mathrm{O}$ values in equations 3 and 4 are the mean daily delta values of the respective local laboratory reference water relative to VSMOW, $b$ is the additive correction factor, and $m$ is the expansion coefficient correction factor. The procedure to apply correction factors is given in Appendix E.

As a check on quality assurance, approximately one-third of the samples are prepared and analyzed in duplicate on different days. If the replicates do not agree within acceptable tolerances, they are analyzed until acceptable statistics are achieved, and samples in the same group that were analyzed only once are analyzed again. The computerized LIMS-LSI will not release data until the statistics are acceptable. The time requirement for performing the analyses described earlier is a minimum of 2 days.

\section{Problematic Samples}

Problematic samples include those with $\mathrm{pH}$ greater than 9. Such samples can consume the $\mathrm{CO}_{2}$ added to the vessel for equilibration. Sufficient $100 \%$ phosphoric acid $\left(\mathrm{H}_{3} \mathrm{PO}_{4}\right)$ with a density of $1.913 \mathrm{~g} / \mathrm{cm}^{3}$ is added to the $2 \mathrm{~mL}$ water sample to lower the $\mathrm{pH}$ to 7.5 .

Salt-water samples (seawater or brine) must be noted by the submitter in advance. $\mathrm{CO}_{2}$ equilibrated with seawater may have a $\delta^{18} \mathrm{O}$ value different from that of $\mathrm{CO}_{2}$ equilibrated, with water having the same isotopic composition but not containing any dissolved salts. This is because oxygen isotopic fractionations occur between the water bound in the hydration sphere of cations and free water, as shown in equation 5.

$$
\mathrm{CO}_{2}(\mathrm{~g}) \stackrel{\alpha}{\Leftrightarrow} \mathrm{H}_{2} \mathrm{O}(\text { free }) \stackrel{\alpha^{\prime}}{\Leftrightarrow} \mathrm{H}_{2} \mathrm{O} \text { (bound) }
$$

The $\mathrm{CO}_{2}$ equilibration technique measures $\mathrm{CO}_{2}$ activity, not concentration ratios. Most of the time, the difference between the two types of isotopic values is not significant. However, in brines, the difference may be significant (Sofer and Gat, 1972, 1975). The $\delta^{18} \mathrm{O}$ values of activity are different from $\delta^{18} \mathrm{O}$ values of concentration, and this difference is proportional to molalities of the major dissolved solids. Data from saline samples can be corrected according to the following equation:

$$
\frac{\delta_{\mathrm{G}}-\delta_{\mathrm{G}}^{\mathrm{S}}}{1+\delta_{\mathrm{G}}^{\mathrm{S}}}=1.11 c_{M g}+0.47 c_{C a}-0.16 c_{K}
$$

where $c$ is the amount concentration of the cations indicated as subscripts and $\delta_{\mathrm{G}}^{\mathrm{S}}$ is the measured $\delta^{18} \mathrm{O}$ of the equilibrated $\mathrm{CO}_{2}$ gas. Note that $\mathrm{Na}$ is not included in the equation because it does not fractionate the oxygen isotopes of water (Sofer and Gat, 1972, 1975; Gonfiantini, 1981; Horita and others, 1994). 


\section{Interferences}

Evaporation alters the isotopic composition of the water; therefore, those samples that were not properly capped are noted and sent back to the sample submitter. Samples with cracked caps can be problematic because they allow evaporation. Caps with foam liners have been especially problematic, because they allow water to evaporate; $\delta^{18} \mathrm{O}$ values could increase by as much as $1 \%$ in 1 month, depending on the volume of the sample.

\section{Troubleshooting and Bench Notes}

If a satisfactory vacuum cannot be attained during sample preparation, the analyst should check to make sure that each vessel is secure in its Cajon fitting and that the O-ring is neither twisted nor damaged. Leak checking may be required. The step-by-step procedure is given in Appendix F.

If any manifold starts shaking violently, the analyst should decrease the frequency of that manifold unit (the knob is located on the shake drive panel) and check to ensure that the manifolds are properly balanced. Even though there may not be samples in some of the ports, the analyst should add either empty bottles or metal plugs into the necessary ports to achieve proper balance.

After every set of analyses, the analyst should inspect the data sheets. If a port is contaminated, as measured by the ratio of the beam monitor and $\mathrm{m} / \mathrm{z}=44$ current for sample and reference gas, or if the sample volume is too small, the analyst should make a note of the port number and notify the supervisor.

\section{Maintenance and Maintenance Records}

The major maintenance is equivalent to maintenance of a vacuum line. This includes checking vacuum pump performance from time to time, changing the diaphragm and pump head as needed, and cleaning and greasing stopcocks and O-rings in fittings on a regular basis. Pump conditions are listed, such as date of diaphragm change, problems, and repairs, in the pump database (File path: LIMS C:IRSILIvacuum pumps). The DI-IRMS does not require regular maintenance; however, it requires a daily maintenance check (Appendix D). A logbook is kept for each DI-IRMS. This logbook includes notes about maintenance checks, normal settings, problems, and repairs.

\section{Sample Retention Time and Disposal}

Samples are retained in the RSIL for at least 6 months after reporting data. Samples are then discarded unless the submitter has requested that the samples be returned.

The sample analysis files from the DI-IRMS computer are kept indefinitely on two different hard disks of the data backup computer. Paper reports are kept for a few weeks. Analytical results from the DIIRMS are transmitted in real time to the LIMS-LSI are kept indefinitely. No data are entered by hand, and no manual calculations are performed on the data. 


\title{
Data Acquisition, Processing, Evaluation, Quality Control, and Quality Assurance
}

\author{
Laboratory Information Management System for Light Stable Isotope (LIMS-LSI)
}

In the RSIL, the LIMS-LSI (Coplen, 2000) is used for data processing and evaluation. This system is a database program capable of (1) storing information about samples, (2) storing the results of mass spectrometric delta values of samples, (3) calculating analytical results using standardized algorithms stored in a database, (4) normalizing delta values using isotopic reference materials, and (5) generating templates to facilitate loading of samples. With this system, the following can be ensured: (1) quality assurance (QA), (2) laboratory efficiency, (3) reduction of workload and errors owing to the elimination of retyping of data by laboratory personnel, and (4) a decrease in errors in data reported to sample submitters. This database provides a complete record of information on how laboratory reference materials have been analyzed and provides a record of what correction factors have been used. It provides an audit trail for the RSIL.

\section{Quality Control (OC) Samples}

Samples commonly are loaded in four groups of 12 because each manifold has 12 sample ports. Approximately seven laboratory local laboratory reference waters are analyzed daily with samples (see Appendix B). Two of these are Antarctic water that is highly depleted in ${ }^{18} \mathrm{O}$, and the other five are laboratory DIW with a typical $\delta^{18} \mathrm{O}$ value. Many reference water positions in a sample template are randomly located among sample ports by the LIMS-LSI. This location allows the analyst to detect problem sample ports. Nevertheless, the analytical result from an occasional reference water is ignored unless the error is persistent or its frequency increases greatly. For NWQL samples, one QC sample is analyzed for every 50 samples submitted. The NWQL provides these QC samples, and their $\delta^{18} \mathrm{O}$ values are unknown to the RSIL. If the NWQL finds any problem with the QC sample data, it reports these observations to the RSIL. Although this happens infrequently, if it did occur, the QC sample in question would be reanalyzed.

An analyst examines the mass spectrometric analysis reports daily for problems. Additive correction factors and expansion factors are determined daily with the LIMS-LSI and applied to isotopic data. After printing the isotopic results from the "Table of Samples in Progress," the analyst reviews the results, determines which samples need to be reanalyzed to achieve acceptable statistics (e.g., $\leq 0.2 \%$ ), and adds those samples back to the "Table of Samples to Be Analyzed" so that they will appear on a sample template.

For each batch of samples completed, a graph is made of $\delta^{2} \mathrm{H}$ plotted against $\delta^{18} \mathrm{O}\left(\delta^{2} \mathrm{H}\right.$ analyses are usually also requested for water samples). The $\delta^{2} \mathrm{H}$ and $\delta^{18} \mathrm{O}$ values of naturally occurring waters commonly have a high natural correlation; the loci of points define the "meteoric waterline." Outliers are noted and reanalyzed for both $\delta^{2} \mathrm{H}$ and $\delta^{18} \mathrm{O}$ because these are either interesting research findings or laboratory errors, such as a mix-up in samples on a sample template.

Every few years, the RSIL participates in an International Atomic Energy Agency (IAEA) interlaboratory calibration. This is a good check of the calibration of the DI-IRMS, the laboratory reference waters, and the computer data management systems.

\section{Acceptance Criteria for All QC Samples}

Acceptance criteria for QC samples are the same as acceptance criteria for the other samples. The rules are as follows: 
- If the standard deviation is less than $\pm 0.15 \%$, use mean delta.

- If there are three or more analyses, delete the outlier and recalculate.

- If standard deviation of this recalculation is $\leq 0.15 \%$, use the mean from this recalculation.

- If none of the above is the case, the result is not accepted, and corrective action is required.

\section{Corrective Action Requirements}

If an analyst finds any problem with the daily reference sample data, the analyst contacts the supervisor. The troubleshooting process will require an evaluation and reanalysis of certain samples to identify the origin of the problem.

If samples do not give satisfactory results after three or more separate analyses, the analyst averages all the data and reports the mean value. Such analytical results are indicated with a comment, and the customer will be advised of the problem by e-mail or other means. If the sample was submitted through the NWQL, it is the responsibility of the customer to determine whether the data need to be qualified. If so, the NWQL will mark the result appropriately in USGS databases.

\section{Responsible Parties for All OA/OC Functions for Procedures Covered in RSIL SOPs}

The analyst, with supervisory approval, is responsible for qualifying data and notifying customers about problematic results.

\section{Data Management and Records}

In addition to evaluating daily sample analyses, an analyst evaluates the data weekly for each project, reports results to the customers, and files final project data reports in the laboratory "Correspondence" binder (Appendix G).

\section{Health, Safety, and Waste-Disposal Information}

\section{Applicable Health and Safety Issues}

\section{Personal Protection}

Safety glasses and protective gloves are recommended whenever samples are handled, especially when the samples are of biological origin. For other precautions and safety procedures, consult the Material Safety Data Sheets (MSDSs), which are on file in the laboratory, and http://www.ilpi.com/msds/\# Manufacturers. This URL provides links to the MSDSs of most chemicals.

\section{Electrical Hazards}

Electrical systems must conform to the National Electric Code, National Fire Protection Association Code (NFPA 70-1971), and the American National Standards Institute (ANSI) Code (C1-1971). For more information, consult the USGS's Safety and Environmental Health Handbook (U.S. Geological Survey, 2002). 
Shock hazards exist inside the instruments. Only an authorized service representative or an individual with training in electronic repair should remove panels or circuit boards where voltages are greater than $20 \mathrm{~V}$. The instruments require a third-wire protective grounding conductor. Three-to-two wire adapters are unsafe for these instruments.

\section{Chemical Hazards}

Mercury is used in the pistons of the DI-IRMS. All samples should be carefully inspected upon receipt for obvious indications of hazards.

\section{Gas Cylinder Handling}

Compressed gas cylinders must be handled and stored according to the Safety and Environmental Health Handbook (U.S. Geological Survey, 2002). Each cylinder must be (1) carefully inspected when received; (2) securely fastened at all times with an approved chain assembly or belt; (3) capped at all times when not in use; (4) capped when transported; (5) transported only by a properly designed vehicle (hand truck); and (6) stored separately with other full, empty, flammable, or oxidizing tanks of gas, as appropriate.

\section{Specific Waste-Disposal Requirements}

Sample containers must be emptied before disposal. Samples to be discarded should be emptied into a container in a sink. The container can catch any copper granules added to the samples, which were analyzed for $\delta^{2} \mathrm{H}$ as well, to prevent them from clogging the sink drain. Copper granules that have been collected from samples should be poured into a bottle and given to the safety health and environment officer for disposal. 


\section{Revision History}

Publication Series and Series Number: Techniques and Methods 10-C2 (Book 10, Section C, Chapter 2)

Publication Title: Determination of the $\delta\left({ }^{18} \mathrm{O} /{ }^{16} \mathrm{O}\right)$ of Water: RSIL Lab Code 489

Publication Authorship: Révész, Kinga, and Coplen, Tyler B.

First Version and Date of First Release: December 2008

Current Version and Date of Current Release: December 2008

Summary of Product Components

\begin{tabular}{|c|c|c|c|}
\hline Component & Description & $\begin{array}{c}\text { Last Revised } \\
\text { In Publication Version }\end{array}$ & $\begin{array}{c}\text { Date of } \\
\text { Last Revision }\end{array}$ \\
\hline & & & \\
\hline & & & \\
\hline & & & \\
\hline
\end{tabular}

List of Revisions (latest version first): 


\section{References Cited}

Clark, I., and Fritz, P., 1997, Environmental Isotopes in Hydrogeology: Boca Raton, Fla., Lewis Publishers, $328 \mathrm{p}$.

Coplen, T.B., 1973, A double-focusing double-collecting mass spectrometer for light stable isotope ratio analysis: International Journal of Mass Spectrometry and Ion Physics, v. 11, p. 37-40.

Coplen, T.B., 1981, Pressure control of gas by a calculator operated mercury piston: Analytical Chemistry, v. 53, p. 940-942.

Coplen, T.B., 1988, Normalization of oxygen and hydrogen isotope data: Chemical Geology (Isotope Geoscience Section), v. 72, p. 293-297.

Coplen, T.B., 1994, Reporting of stable hydrogen, carbon, and oxygen isotopic abundances: Pure and Applied Chemistry, v. 66, p. 273-276.

Coplen, T.B., 1996, New guidelines for reporting stable hydrogen, carbon and oxygen isotope-ratio data, Geochimica et Cosmochimica Acta, v. 60, p. 3359-3360.

Coplen, T.B., 2000, A guide for the laboratory information management system (LIMS) for light stable isotopes-Version 7 and 8: U. S. Geological Survey, Open-File Report 00-345, p. 121.

Coplen, T.B., Kendall, C., and Hopple, J., 1983, Intercomparison of stable isotope reference samples: Nature, v. 302, p. 236-238.

Epstein, S., and Mayeda, T., 1953, Variation of ${ }^{18} \mathrm{O}$ content of waters from natural sources: Geochimica et Cosmochimica Acta, v. 4, p. 213-224.

Gonfiantini, R., 1981, The $\delta$-notation and the mass-spectrometric measurement techniques, chap. 4 of Stable isotope hydrology; deuterium and oxygen-18 in the water cycle (J.R. Gat and R. Gonfiantini, eds.), International Atomic Energy Agency, Technical Reports Series No. 210, p. 35-85.

Horita, J., Cole, D. R., and Wesolowski, D. J., 1994, The activity-composition relationship of oxygen and hydrogen isotopes in aqueous salt solutions: III. Vapor-liquid water equilibration of $\mathrm{NaCl}$ solutions to $350^{\circ} \mathrm{C}$ : Geochimica et Cosmochimica Acta, v. 59, No. 6, p. 1139-1151.

Roether, W., 1970, Water- $\mathrm{CO}_{2}$ exchange set-up for routine 18-oxygen assay of natural waters: International Journal of Applied Radiation and Isotopes, v. 21, p. 379-387.

Sofer, Z., and Gat, J. R., 1972, Activities and concentrations of oxygen-18 in concentrated aqueous salt solutions: Analytical and geophysical implications: Earth Planetary Science Letters, v. 15, p. 232-238.

Sofer, Z., and Gat, J. R., 1975, The isotope composition of evaporating brines: Effect of the isotopic activity ratio in saline solutions: Earth Planetary Science Letters, v. 26, p. 179-186.

U.S. Geological Survey, 2002, USGS Handbook 445-3-H, Safety and Environmental Health Handbook, $435 \mathrm{p}$. 


\section{Appendix A. Step-by-Step Procedure to Log In Samples to LIMS-LSI}

\section{Submittal Types}

1. Samples submitted to RSIL for analysis are sent either through NWQL or directly to RSIL by the person or agency requesting an analysis.

2. There are two primary types of submittals:

a. ASR, which uses ASR forms for each sample submitted.

b. Direct, in which all sample information is submitted via diskette, $\mathrm{CD}$, or e-mail.

\section{ASR Submittal}

1. Match up the information on the sample bottles with the information on the ASR forms by spreading out the ASR forms and placing each bottle on its respective ASR form. Each sample must have a corresponding ASR form.

2. At this time, check for any broken or damaged sample bottles.

Assign National Water Information System (NWIS) Numbers to Samples

1. Use the format 00 (year) 000 (Julian date) 95 (standard \#) 00 (sample \#).

2. The Julian date is found on the standard-issue calendar used in the laboratory. It is the number in red located under the day of the month.

3. The sample number is derived from the number of samples submitted, starting with 00 for the first sample, 01 for the second sample, 02 for the third sample, and so on.

4. An example of format would be as follows: 071389504-07 for the year 2007, 138 for the 18th of May, 95 (which is a standard number), and 04 to indicate the fifth sample in the group.

5. If there are two or more groups of samples logged in on the same day, the sample number(s) will be different for each group. If the last sample of the first group that was logged in is 071389504 , then the first sample of the second group would be 071389505.

6. Add any QC samples to the group (explained in next section) and assign NWIS number(s).

7. Write in NWIS numbers, assigned in step 2, in the space provided on the top left hand side of the ASR form marked NWIS RECORD NUMBER, SAMPLE TRACKING ID.

\section{QC Samples (NWOL Samples Only)}

1. QC samples must be checked before logging samples into the LIMS database.

2. For every 50 samples submitted thru NWQL, a QC sample must be added (see the laboratory supervisor for the location of QC samples).

3. An additional Julian date (explained in the next section) will need to be created as a placeholder for the QC sample to be correctly added to the LIMS database.

4. To determine whether a QC sample is required, reference the yellow QC sample log sheet located on the wall to the right of the LIMS printer.

a. There are four columns on the QC sample log sheet: project date, start W\#, end W\#, and \# of samples.

b. QC sample numbers begin with the prefix QC followed by three " 0 s," that is, QC-00038, QC00040, QC-000120, and so forth.

c. Add up the numbers in the "\# of Samples" column from the last QC number.

d. After the 50th submitted sample, a QC sample must be added. 
Logging Samples Into the LIMS-LSI Database

1. Open the LIMS program.

2. Select "New Project Login."

3. In the "New Project Login" window:

a. Submission date: the date samples are logged in (e.g., 5/21/07).

b. Customer: type in or use drop-down menu to select. For NWQL samples, always select "Mullin, Ann H." from the drop-down menu. This is not found on the ASR form.

c. Medium: This is determined by the type of sample submitted, that is, "01 Water." This information is not found on the ASR form.

d. Project purpose or title: For example, Central Lab Samples, Schedule \#, submitter or collectors name (District contact e-mail).

e. Location: Type in the location of the samples, if provided.

f. Country: Select from the drop-down menu.

g. State and county: Select from the drop-down menu.

h. NWQL media: Select from the drop-down menu; this is indicated as "Medium Code" on the ASR sheet.

i. Lab code/schedule: This is on the ASR form listed under "Analytical Work Requests." The type of schedule submitted will determine whether the sample number will begin with a "W," "G," or "S." Use W for hydrogen and oxygen isotopes of water samples.

Adding the QC Sample

1. The addition of the QC sample may fall at the beginning of the sample group, at the end of the sample group, or somewhere in the middle.

2. Treat the QC sample as one of the samples of the sample group and assign it a Julian date, just like the samples. The only difference is it will not have an ASR form.

3. While editing samples in the "Samples" window, delete the placeholder that was assigned to the QC sample in the "Field ID/NWQL Number" space and replace it with the QC number.

Generating Unique RSIL Lab ID by LIMS-LSI (W-numbers in case of water isotopes)

1. In the "New Samples Log-In" window, click "Add Range."

2. In the "Add Range" box, there are two fields: "From" and "To."

3. Type in the NWQL numbers for that group from the lowest to the highest, that is "From" 071439500 "To" 071439507. Do not forget QC sample, if any.

4. Check that the information entered is correct, then click "Add."

5. The "Add Range" window will pop up for confirmation of the number of rows (samples) added. If correct, click "Yes."

\section{Save Information Into Project Record}

1. When all information has been entered, click "Save" in the "Login New Samples" window.

2. In "LIMS" window, click "OK" to create a project record in the LIMS system.

3. If any of the information in the project record needs to be edited, go to the LIMS main page and click "Projects."

4. In the "Find Project" window, select the project and double click to open.

5. From the "Projects" window, all information can be viewed and edited. 


\section{Entering Information for Each Sample}

1. Information for each individual sample must be entered into LIMS from its corresponding ASR form.

2. From the LIMS main page, click "Projects."

3. Select and double click the project to edit.

4 In the "Projects" window, click "Samples."

5. In the "Samples" window, click "Edit."

6. Fill in each sample's information using the ASR form.

7. When field has been completed, click "Save."

8. Do this for each sample using the left or right arrow buttons found on either side of the sample number.

9. When all the samples have been entered, click "Close."

\section{Print Report}

1. Print two copies of the submission report.

2. In the "Projects" window, click "Print Report" twice.

3. Update the QC log if any QC samples were added.

\section{Print Sample Labels}

1. Print two sets of labels, except for waterproof labels.

2. There are three options for printing labels:
a. "Print Labels"-blue labels, 30 per page.
b. "Print Small Labels," —small white labels, 80 per page.
c. "Print Waterproof Labels,"-white labels, 27 per page.

3. The selection of labels will depend on the size of sample bottles submitted and whether samples need refrigeration where waterproof labels may be necessary. Ask the laboratory supervisor for guidance.

4. Blue labels are normally used for the ASR forms; white labels are used for small bottles.

NWQL Headings

1. Obtain a diskette.

2. Insert diskette into the appropriate drive.

3. In the "Projects" window, click "NWQL Headings."

4. Follow the directions on the computer.

5. When data have been transferred, click "Close" to cancel the projects.

6. Leave the diskette in the drive at this time.

Print Sample Range

1. On the main LIMS page, click "Print Sample Range."

2. Select a prefix, for example, "W" for water.

3. Type in the range from the lowest to the highest sample number in the project in the "From" and "To" spaces provided.

4. Click "Print."

5. This information will be mailed back to NWQL.

6. The diskette can be removed at this time. 
Placement of the Labels

1. Place the correct label on the corresponding ASR form (blue labels) in the space in the upper right hand side marked "Lab Use Only," "NWQL Laboratory ID."

2. Place the other label on the corresponding sample bottle.

3. Crosscheck all information to ensure the labels on the ASR forms and bottles match.

Information to Be Mailed Back to NWQL

1. Photocopy all ASR forms.

2. The photocopied set goes into a manila envelope.

3. Include "Sample Range" printouts.

4. Place a preaddressed label to NWQL onto the front of the envelope.

5. Write mail stop 431 and the name of the laboratory supervisor in the top left corner.

6. Put the envelop in the mail stop out box.

E-Mail Headings to Sample Submitter

1. This information is on the diskette used in the NWQL headings section.

2. Access the correct drive on the computer and open the file with NotePad.

3. Right click in the NotePad window, click "Select All," right click again, and select "Copy."

4. Use Lotus Notes, open a "New Memo," right click, and select "Paste" to transfer all data into e-mail.

5. Delete the first three lines of the e-mail.

6. Enter the e-mail address of the submitter (District contact e-mail) and cc the laboratory supervisor (isotopes).

7. Print a copy of the e-mail and send.

Samples in Progress Binder

1. Take a printed copy of the e-mail along with a copy of the project report and place it in the "Samples in Progress" binder.

2. The projects are in order by date.

3. Arrange in a binder with the project report on top, copy of the e-mail second, and any other documentation received from the submitter.

4. Place a divider after each project as it is placed in the binder.

Central Laboratory Sheets Binder

1. Place the project report and the original ASR forms in the back of the binder.

2. Use "write on" tape and record the submission date of the sample group. Place the tape on the edge of the project report to be used as a tab.

Direct Submittals

Direct Submittal Formats

1. RSIL Sample Submittal Form. 
2. RSIL Alternative Sample Submittal Form.

3. Both types can be submitted via a $\mathrm{CD}$, diskette, or e-mail.

\section{Verifying Information}

1. Place the submitted diskette into the appropriate drive and print out the "Sample Submittal File" if the submitter has not already provided a paper copy.

2. Ensure that the information provided matches the information on the sample bottle labels.

3. Change the submission date on the submittal file to the date that the samples are actually being logged in.

4. Save any changes before exiting.

Logging Samples Into the LIMS Database

1. Open the LIMS program.

2. From the LIMS main page, select "Import New Project."

3. In the "Import Project" window, select the file being submitted.

4. In the "How Many Samples in Project" window, click "OK."

5. In the "LIMS" window click "OK."

\section{Getting a Password}

1. A password is required if latitudes and longitudes are not provided in the submittal file.

2. See the laboratory supervisor for a password.

3. If some other information is missing and LIMS does not allow you to log in the samples, send the diskette back to the customer for missing information.

\section{Printing the Report and Putting Samples into Template}

1. On the main LIMS page, select "Projects."

2. Select and double click the project to edit.

3. Only one copy of the submission report needs to be printed.

4. In the "Projects" window, click "Print Report" once.

5. In the "Project" window, click "Templates" and then add the project to either the front or end of the queue for the appropriate mass spectrometer(s).

\section{Printing Labels}

In the "Project" window, click "Print Label" and follow the instructions for "Print Sample Range" except when only one set of labels needs to be printed.

\section{Filing Samples in Progress Binder}

1. Take the printed copy of the submission report and submittal file printout along with any other documentation and place it in the "Samples in Progress" binder.

2. The projects are in order by date. 
3. Arrange in the binder with project report first, along with any other documentation received from the submitter.

4. Place a divider after each project as it is placed in the binder.

Placing Labels

1. Match the label to the sample bottle.

2. Ensure all information is correct using the submittal form.

\section{Preparation of Samples (This Applies to All Samples)}

1. Check to ensure that samples are labeled.

2. Check samples for hydrogen sulfide $\left(\mathrm{H}_{2} \mathrm{~S}\right)$ and organic material.

3. Using a suitable storage box (see Laboratory Supervisor), place samples in order.

\section{Checking for $\mathrm{H}_{2} \mathrm{~S}$}

1. Open bottle and check cap to ensure it is a Polyseal type cap. Replace any caps that are not Polyseal caps.

2. Open bottle and add two scoops ( $0.70 \mathrm{~g}$ per scoop) of copper. This applies to all samples except precipitation samples.

3. Replace cap and shake.

4. Open bottle and sniff for $\mathrm{H}_{2} \mathrm{~S}$ (rotten egg smell).

5. Add more copper, shake the sample, and check for $\mathrm{H}_{2} \mathrm{~S}$ smell again.

6. If the sample has an extremely strong $\mathrm{H}_{2} \mathrm{~S}$ smell, subdivide the sample into a smaller (11-mL) bottle and add copper to that as before until no smell is present.

7. Print a duplicate label (the same as the original sample) and place it on the subsample bottle.

8. Use a rubber band to attach the subsample bottle to the original sample bottle.

\section{Checking for Organic Material}

1. Hold the sample up to the light and check for cloudy or yellowish colored samples, which is an indication that organic material is present.

2. Using a small spatula, add up to two scoops ( $0.50 \mathrm{~g}$ per scoop) of granular activated charcoal.

3. Replace cap and shake.

4. Place the sample in the appropriate storage box in order by sample number. 


\section{Appendix B. Step-by-Step Procedure to Print a Template and a Samples- to-Be-Analyzed List}

\section{Template}

1. Use "Print Template" in LIMS-LSI.

2. Select the appropriate template for Dupont IRMS, which is "Neptune."

3. Design analysis sequence with 32 ports.

4. Click "New Template."

5. Add any sample information you want in column "Sample/Extraction Info."

6. Click "Print."

7. Insert the diskette to receive sample headings.

8. Click "OK."

9. Exit LIMS-LSI.

10. If the sample amount is different that $2 \mathrm{~mL}$, write on the template the sample amount $(\mathrm{mL})$ needed in each vial and the equilibration time. The date that samples should be analyzed should be written on both the template and the diskette.

11. Put them near to the $\mathrm{CO}_{2}$ IRMS computer. 
Samples to be Analyzed List

W-62000 and W-63333 are reference waters

5/29/2008 5:35:24 PM

\section{Neptune Samples To Be Analyzed}

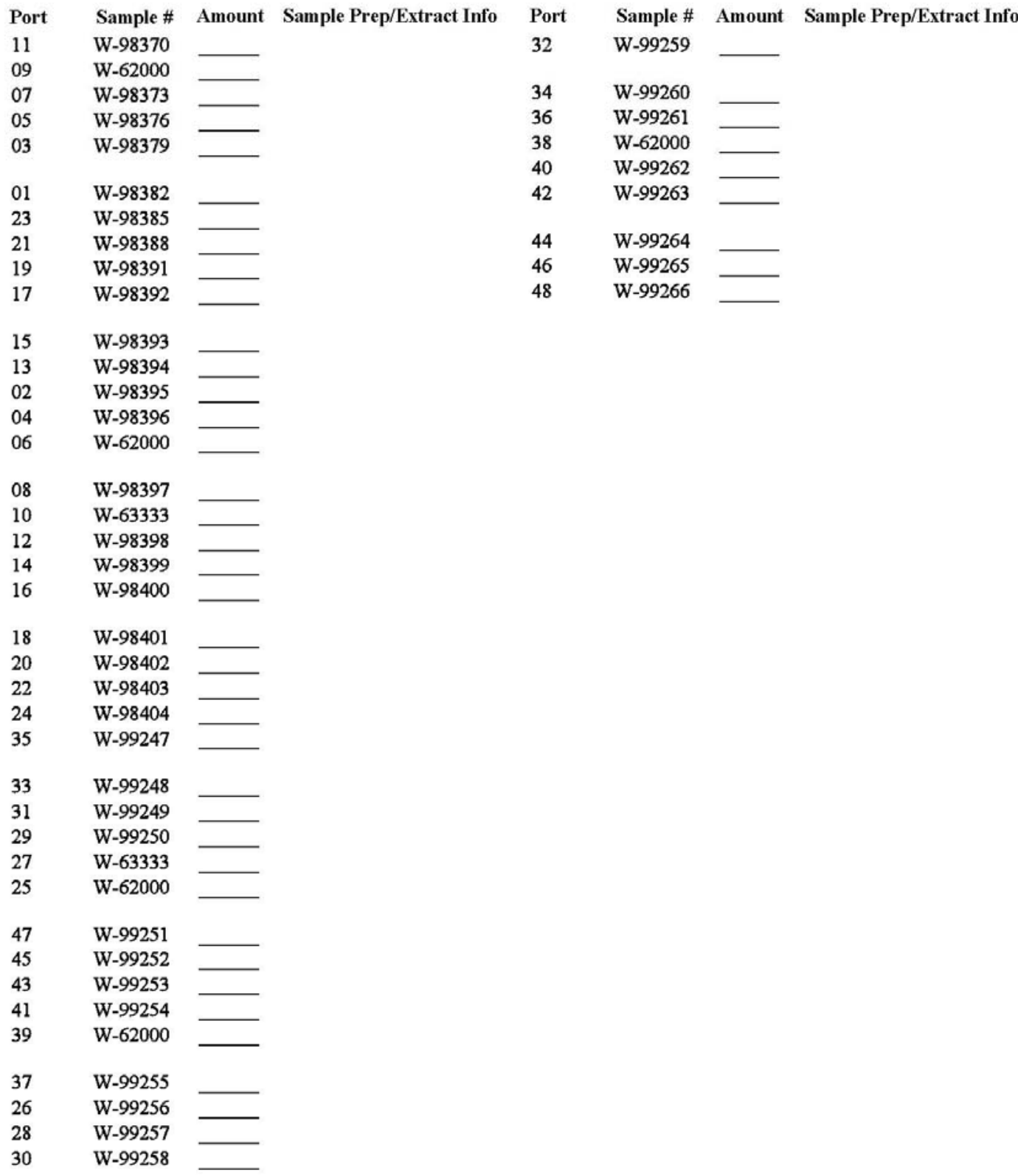



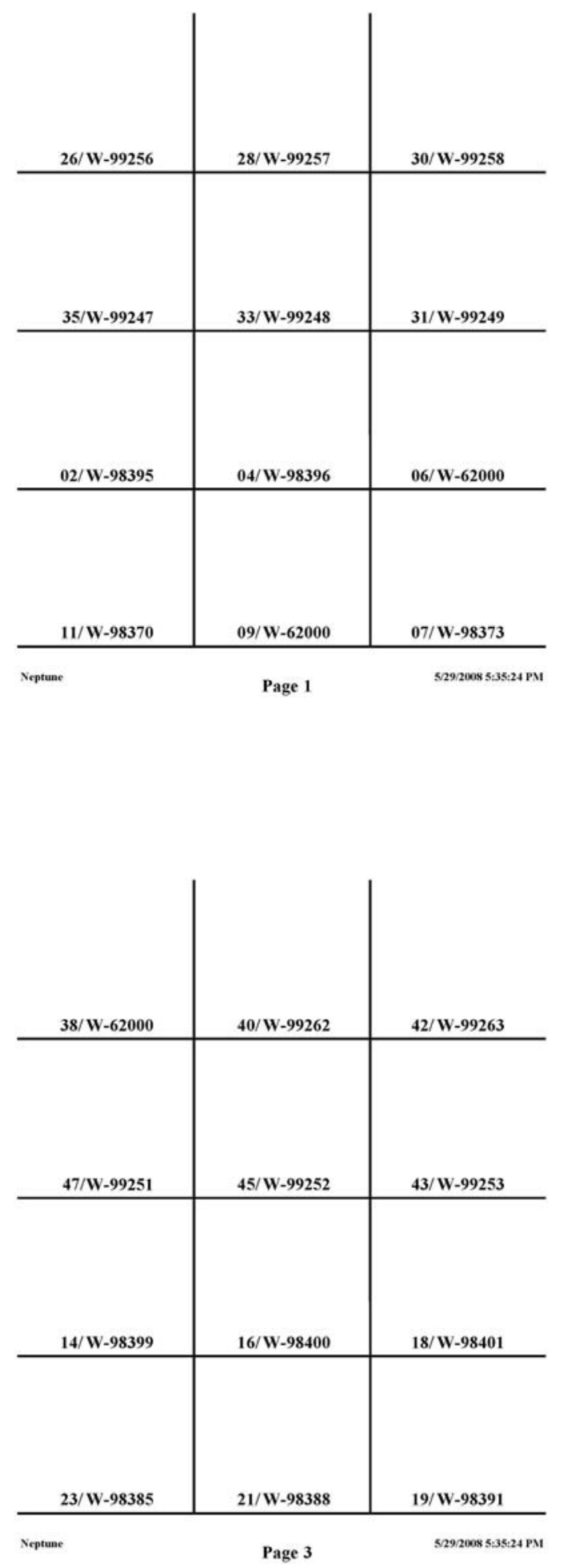
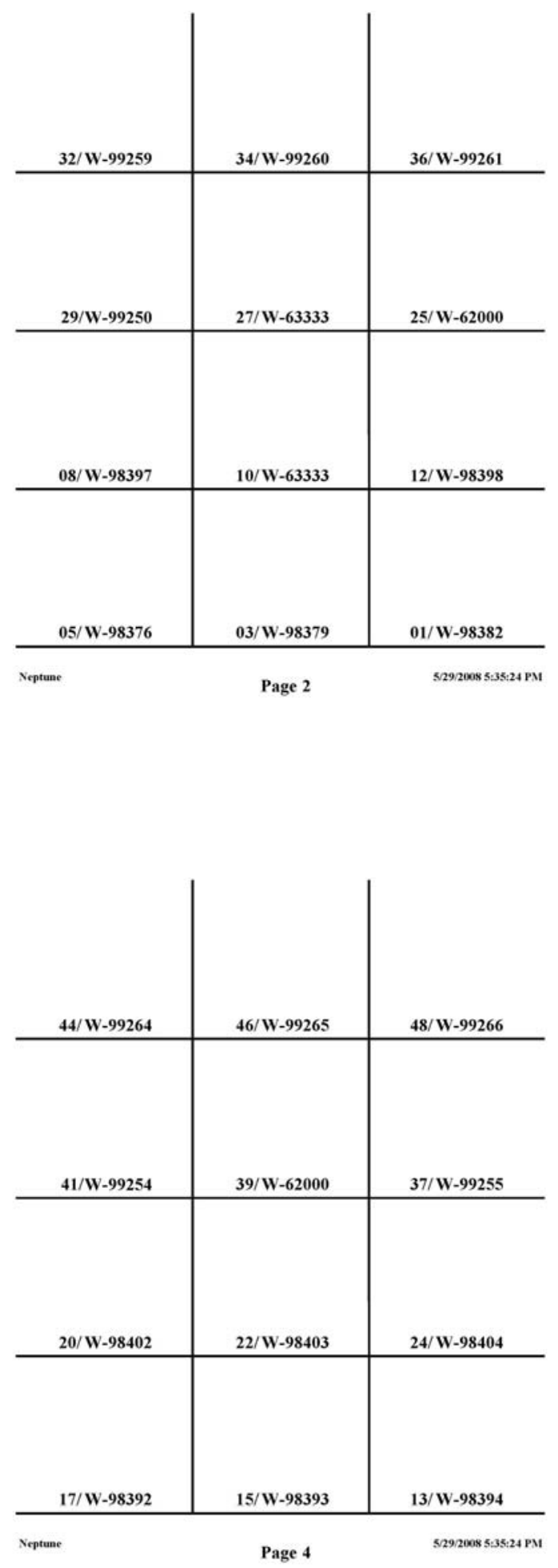


\section{Appendix C. Step-by-Step Procedure to Prepare and Analyze Samples on the $\mathrm{CO}_{2}$ Equilibration Line}

These items should be checked off as you work.

\section{System Preparation}

1. Remove Micromass stainless steel water traps and glass sample vessels from oven for later use.

2. Wait until all water samples have been analyzed.

3. Inspect analysis sheets to ensure samples were analyzed properly.

4. Turn off both temperature controllers.

5. Remove the plastic air-bath cover on samples 1 to 24 and plastic doors on samples 25 to 48 .

6. Remove the sample vessels from port valves.

7. Insert stainless steel plugs into solenoid valves.

8. Open the ballast toggle vale.

9. Evacuate the solenoid-valve condensate:

a. Check or set to GREEN: COMP, M/S, PUMP, ISO A, ISO B, ISO C, and ISO D.

b. Check or set to RED: BANK A, BANK B, BANK C, BANK D, and 1-12.

10. Note time:

11. Close both toggle valves above the Micromass stainless steel water trap.

12. Remove the Micromass stainless steel trap by taking Ultratorr fittings off completely.

13. Install a clean Micromass stainless steel water trap removed from oven in step 1.

14. Open both toggle valves above the Micromass stainless steel water trap. (Do not add dry ice or $\mathrm{LN}_{2}$.)

15. Wash sample vessels with two rinses DIW and put in the oven.

16. Turn on the Pirani gauge and change multiplexer to 01 to read the Pirani gauge.

17. Wait until 40 min have elapsed from time mark in step 10.

18. Close ballast toggle valve. (The Pirani gauge should be $7.8 \mathrm{~V}$ or better.)

19. Wait for the absolute value of the Pirani gauge to drop below $4 \mathrm{~V}$ (or Edwards calibrated APG to drop below 0.04 mbar).

20. Close valves. Set to GREEN: BANK A, BANK B, BANK C, BANK D, and 1-12.

21. Remove stainless steel plugs from sample ports.

\section{Water Sample Preparation}

1. Load sample vessels as follows:

a. Put 12 dry sample vessels in the first (front) row of the plastic sample preparation rack.

b. Load sample into first vessel.

i. Mix sample by inverting bottle three times.

ii. Put a pipettes tip on pipetter.

iii. Remove cap from sample bottle.

iv. Withdraw 2-mL sample from bottle and transfer into first sample vessel, being careful to avoid drops of sample on outside or top of sample vessel.

v. Eject pipette tip into trash container.

vi. Move first sample vessel from first to second row of rack.

vii. Secure cap on bottle to eliminate any evaporation.

viii.Return sample bottle to appropriate storage box at left of sample preparation area.

c. Repeat steps a and b for the remaining samples in the rack. Reference samples in ampoules can be opened by inserting them into a pipette tip to protect skin during breaking. 
d. Place the plastic sample preparation rack on top of the Micromass shaker with pegs protruding into the hole in the base of the plastic rack. Put rubber bands around the solenoid motor and the left handle of plastic rack to prevent the rack from moving.

e. Load samples into the ports, twisting as you insert. Load as though you were reading a bookstart at the top left and go full right, then move to bottom left and go full right.

2. Repeat above for the remaining samples. Place the plastic rack on the Micromass counter top as necessary.

3. Start shakers. Set to RED: SHAKER AB and SHAKER CD.

4. Replace the air-bath cover and doors.

5. Turn on both temperature controllers.

6. Note time

7. Open vessels to the pump.

a. Check or set to GREEN: MS, ISO A, ISO B, ISO C, and ISO D.

b. Check or set to RED: PUMP, BANK A, BANK B, BANK C, BANK D, and 1-12.

8. Put away old samples and discard old template.

9. Wait until 15 min have elapsed from time mark in step 6.

10. Add $\mathrm{LN}_{2}$ to dewar of the Micromass stainless steel water trap (located below two toggle valves).

11. Open vessels to the Micromass stainless steel water trap:

a. Check or set to GREEN: BANK A, BANK B, BANK C, and BANK D.

b. Check or set to RED: PUMP, ISO A, ISO B, ISO C, ISO D, and 1-12.

12. Wait for $1 \mathrm{~min}$.

13. Set to RED: BANK A.

14. Wait for the Micromass thermocouple gauge to reach $4 \mathrm{mV}$ (approximately $5 \mathrm{~min}$ ).

15. Set to RED: BANK B, BANK C, and BANK D.

16. Wait for the Micromass thermocouple gauge to reach $4.6 \mathrm{mV}$ (approximately $5 \mathrm{~min}$ ).

17. Close vessels: BANK A, BANK B, BANK C, BANK D, and 1-12 GREEN.

18. Close both toggle valves above the Micromass stainless steel water trap.

19. Remove the $\mathrm{LN}_{2}$ dewar from the Micromass stainless steel trap.

20. Remove the Micromass stainless steel water trap by taking Ultratorr fittings off completely and then putting the trap in the oven.

21. Install the cool Micromass stainless steel water trap removed from the oven in step 1 of System Preparation.

22. Open both of the toggle valves above the Micromass stainless steel water trap. (Do not add dry ice or $\mathrm{LN}_{2}$.)

\section{Adding Carbon Dioxide and Changing the Micromass Water Trap}

1. Close the $\mathrm{CO}_{2}$ tank toggle valve.

2. Check or set to RED: PUMP and M/S.

3. Check or set to GREEN: ISO A, ISO B, ISO C, and ISO D.

4. Check or set to UNLIT position valve 98.

5. Open the $\mathrm{CO}_{2}$ line toggle valve.

6. Wait until the Micromass thermocouple gauge reaches $3.5 \mathrm{mV}$.

7. Check or set to RED: ISO A, ISO B, ISO C, and ISO D.

8. Close the $\mathrm{CO}_{2}$ line toggle valve.

9. Open the $\mathrm{CO}_{2}$ tank toggle valve.

10. Set to GREEN: PUMP.

11. Open the $\mathrm{CO}_{2}$ line toggle valve (pressure gauge should be at $1 / 2 \mathrm{~atm}$ ). 
12. Set to RED: BANK A, BANK B, BANK C, BANK D, and 1-12 RED. (Note, you should see an increase in the Bourdon gauge on Bank A. Also ISO A, ISO B, ISO C, ISO D, M/S are RED, and PUMP is GREEN).

13. Mark the time

14. Collect the new samples from storage cabinets and begin setting up new template with samples, if available. Put away old samples and recycle old paper template. Proceed to next step when 3 min has elapsed from the time marked in step 13.

15. Record the time on the daily sheet.

16. Close the vessels. Set to GREEN: BANK A, BANK B, BANK C, BANK D, and 1-12.

17. Close the $\mathrm{CO}_{2}$ tank toggle valve.

18. Evacuate the $\mathrm{CO}_{2}$ line. Set to RED: PUMP.

19. Wait $1 \mathrm{~min}$.

20. Close the $\mathrm{CO}_{2}$ line toggle valve.

21. Check or set to GREEN: ISO A, ISO B, ISO C, and ISO D.

22. Turn off the Pirani gauge.

23. Put dry-ice slush in dewar and load on the Micromass stainless steel water trap and attach foam cover.

\section{Starting Program}

1. Set to GREEN: M/S.

2. Set to RED: COMP.

3. Load new headings from the daily diskette and then select "Data" and select "Load New Headings" from the controller display.

4. If any samples on the template have been changed, edit the list by selecting "Data" and selecting "Edit" from the controller display.

5. Print new headings by selecting "Data" and then selecting "Print Headings" from the controller display.

6. Go through the $\mathrm{CO}_{2}$ mass-spectrometer checklist.

7. Start the analysis program by selecting "Multi sample" and then selecting "Analyze Samples." Select $7 \mathrm{~h}$ for equilibration unless more time is needed for small or for brine samples. Do not skip capillary stabilization time if $\mathrm{CO}_{2}$ will not have been flowing into the sample capillary when samples start running. 


\section{Appendix D. Step-by-Step Procedure for $\mathrm{CO}_{2}$ Mass Spectrometer Checklist}

These items are to be checked off as you inspect them!

\begin{tabular}{|l|l|l|l|l|l|l|l|}
\hline \multicolumn{1}{|c|}{ Days of the week } & M & T & W & Th & F & S & S \\
\hline 1. Reference gas loaded as necessary & & & & & & & \\
\hline 2. Enough standard gas for the night & & & & & & & \\
\hline 3. Piston Hoke valves open/sidearm closed & & & & & & & \\
\hline 4. All four piston lights on & & & & & & & \\
\hline 5. Check piston N $\mathrm{N}_{2}$ pressure 3 psi & & & & & & & \\
\hline $\begin{array}{l}\text { 6. Check pressure (p) of } \mathrm{N}_{2} \text { tanks: piston tank pressure }>200 \\
\text { psi and Valve tank pressure }>1000 \text { psi }\end{array}$ & & & & & & & \\
\hline 7. Check printer paper/clean ink cartridge & & & & & & & \\
\hline 8. Minor peak centered and focused on 280 & & & & & & & \\
\hline 9. Wash used vessels and put in oven & & & & & & & \\
\hline 10. CO line toggle valve closed & & & & & & \\
\hline 11. Toggle valves on slush trap open & & & & & & & \\
\hline 12. Computer control button on red & & & & & & & \\
\hline 13. Water vessels shaking & & & & & & & \\
\hline 14. Equilibration line temperature $=25 \pm 0.1^{\circ} \mathrm{C}$ & & & & & & & \\
\hline 15. Dry ice slush replenished at end of day & & & & & & & \\
\hline 16. All valves on auto (especially 91, 93, and 98) & & & & & & & \\
\hline 17. Open the gas sample stopcocks & & & & & & & \\
\hline 18. Stay to watch the first gas sample run
\end{tabular}




\section{Appendix E. Step-by-Step Procedure to Determine and Apply Correction Factors and Evaluate Data}

1. Open "Correction Factors and Normalization Equations" in LIMS-LSI.

2. Select the IRMS and isotope, such as "Neptune for ${ }^{18} \mathrm{O} . "$

3. Select "Query."

4. Double click on the last sample analyzed on that day.

5. Evaluate data of the reference materials. Ignore outliers; there should not be more than 1 or 2 outliers.

6. Choose "Normalize with All References."

7. Accept "Expansion Correction and Additive Correction Factors."

8. Print out correction factor sheet.

9. Report daily reference values and correction factors along with date and range of analysis number to the "Neptune" binder.

10. Go back to the LIMS-LSI main menu by closing open windows.

11. Choose "Print Samples in Progress," and
a. Open "Samples in Progress."
b. Choose the appropriate isotope.
c. Choose the appropriate prefix (W for water).
d. Put in the sample ID range from the "Samples-to-Be-Analyzed" sheet. Click Print.

12. Review the results; determine repeats.

13. Put the repeats back in "Table of Samples to Be Analyzed."
a. Go back to the LIMS-LSI main menu.
b. Open "Print Templates."
c. Select the appropriate template name for the IRMS with which the samples are analyzed.
d. Find the sample in the "List of Samples."
e. Change "Repeats" from 0 to 1.
f. Close windows and exit LIMS-LSI. 


\section{Appendix F. Step-by-Step Procedure to Leak Check Valves}

1. Mount the plugs or dry vessels on the ports and install a clean, dry stainless steel U-tube trap.

2. Change the IRMS multiplexer to the Micromass thermocouple gauge (\#05) and push "auto" range button on the digital multimeter.

3. Evacuate all 48 ports: Set PUMP, ISO A, ISO B, BANK A, BANK B, and 1-12 to RED; set MS to GREEN.

4. When the thermocouple gauge reads $4.0 \mathrm{mV}$, close off the U-tube trap and gauge from the pump: set the PUMP to GREEN.

5. Put liquid nitrogen in dewar on U-tube trap.

6. When the thermocouple gauge attains a value of $5.0 \mathrm{mV}$, close the manifolds and valves: set ISO A, ISO B, BANK A, BANK B, and 1-12 to GREEN.

7. Wait 5 to 10 min and then check manifolds one at a time: set ISO A to RED, then set ISO A to GREEN and ISO B to RED.

8. Check valves in pairs: set ISO A, ISO B, BANK A, and BANK B to red; set 1-12 to RED for a few minutes and then back to GREEN. If the vacuum gauge shows a substantially poorer vacuum, there is a leak.

9. If a leak is indicated, valves should be checked individually. To check the valves on manifold A, set ISO A and BANK A to red and then set the suspect valve to RED for a few minutes and then to GREEN; for valves on manifold B, repeat with ISO B.

10. Evacuate the manifold between each valve test if necessary. If the thermocouple gauge reading increases while the PUMP is closed, determine whether the rate of increase is faster or slower when manifolds or valves are opened to vacuum. 


\section{Appendix G. Step-by-Step Procedure to Report Data}

1. Open "Store Samples in Progress" in LIMS-LSI.

2. Choose the appropriate isotope.

3. Choose sample ID range from "Sample in Progress" print out.

4. Store data.

5. Go back to the LIMS-LSI main menu.

6. Open "Project" and find the appropriate project in the list.

7. Select "Print Report" and check whether the project report contains all the results. If not, search for the missing results in the database.

8. Select "Results," transfer data in Excel format or (and) text format to a diskette, and report data to customer through e-mail.

9. Click "Print Report" to print a project report and put it in the "Correspondence" binder along with all other documents in the "Samples In Progress" binder that are related to this project.

10. If the samples were submitted through the NWQL, click "NWQL Export" and transfer data in NWQL format to a disc; report these data to the NWQL by e-mail. Print a copy of the NWQL export file and save in the "Correspondence" binder with the project report printed in step 9. 